\title{
Biological Significance of Hetero-Scaffolds Based Gold(III) Complexes
}

\author{
Darshana N. Kanthecha, ${ }^{1}$ Dilip B. Raval, ${ }^{2}$ Vasudev R. Thakkar ${ }^{2}$ \\ and Mohan N. Patel ${ }^{1, *}$ \\ ${ }^{1}$ Department of Chemistry, Sardar Patel University, Vallabh Vidyanagar-388 120, \\ Gujarat, India, Phone number: (+912692) 226856²18 \\ ${ }^{2}$ B. R. Doshi School of Bioscience, Sardar Patel University, Vallabh Vidyanagar-388 120, Gujarat, India \\ *Corresponding author: E-mail: jeenen@gmail.com
}

Received: 18-11-2017

\begin{abstract}
Synthesized ligands and complexes, $\left[\mathrm{Au}\left(\mathrm{L}^{\mathrm{n}}\right) \mathrm{Cl}_{2}\right] \mathrm{Cl}$, have been characterized by various techniques such as elemental analysis, LC-MS, FT-IR, UV-Vis, ${ }^{1} \mathrm{H}$ and ${ }^{13} \mathrm{C}$ NMR spectroscopy, conductance measurement and magnetic moments measurement. The experimental results show that complexes exhibit higher antibacterial activity against $\mathrm{Gram}^{(+\mathrm{ve})}$ and $\mathrm{Gram}^{(-\mathrm{ve})}$ microorganisms than free ligands. The in vitro cytotoxicity and cellular level cytotoxicity suggest that $\mathrm{Au}(\mathrm{I}-$ II) complexes show better activity than corresponding ligands. The DNA interaction study has been evaluated using absorption titration. The experimental evidence indicates $\left(K_{\mathrm{b}}=1.08-3.44 \cdot 10^{5} \mathrm{M}^{-1}\right)$ that all the complexes have been bind to HS-DNA by intercalation mode. To further verify the nature of interaction viscosity measurement and molecular modeling have been carried out which suggest the intercalation binding between complex and DNA. The Schizosaccharomyces pombe cell DNA cleavage has been performed using agarose gel and their photographic images of complexes show smearing of DNA due to DNA cleavage from the nucleus.
\end{abstract}

Keywords: Gold(III) complexes; DNA interaction; molecular modeling; antibacterial activity; Schizosaccharomyces pombe cell

\section{Introduction}

A recent discovery is focused on metal based chemotherapeutics targeting the double-helix DNA, due to the interesting structural diversity of metal complexes caused by different coordination numbers and types of ligands. DNA binding study with metal complexes expand knowledge in molecular biology, which show the possibilities of specifically targeting therapeutically related proteins or enzymes. ${ }^{1-3}$ It is a challenging task to design a metal-based drug, which may be applicable to various medical treatments. The successful use of cisplatin as drug in medicine raises the interest in the study of metal complexes and their various biomedical applications. ${ }^{4}$ Complexes with square planar geometry ( $\mathrm{d}^{8}$ system), isoelectronic and isostructural to platinum(II) complexes have been designed as potential alternatives for binding with DNA. ${ }^{5}$ DNA binding has gained main attention on biological activities because DNA contains exact genetic data for maintaining the function of cell growth. DNA replication is essential for the life cycle of biological organisms. The alteration of the DNA replication occurs when the drugs bind to the site of the DNA, which leads to the inhibition of the DNA replication. The drugs that exhibit such types of alteration in DNA are known as anticancer agents. Also, metal complexes can interact with biomolecules irreversibly and enhanced the effectiveness and lower the dosages for in vivo application. Cytotoxicity of drugs is habitually associated with their DNA-binding properties. ${ }^{6,7}$ Therefore, DNA interaction study has a great importance for the design of new transition-metal drugs and their biological applications. ${ }^{8}$ Application of gold(III) complexes are interesting and developing topics in the area of nanomaterial, nanotechnology, and catalyst. ${ }^{9}$ In the last decade, new studies of gold(III) complexes have been focused on the treatment of cancer, ${ }^{10}$ rheumatoid arthritis, ${ }^{11}$ $\mathrm{HIV},{ }^{12}$ malaria $^{13}$ and antiproliferative action. ${ }^{14}$ Comparatively, metals, including nickel, cadmium, chromium, and arsenic, can prompt carcinogenesis and hence are less favorable to the body. These limitations have triggered a search for platinum/gold-based compounds that show low- 
er toxicity, higher selectivity and a broader spectrum of activity. ${ }^{15}$ By following the interactions between gold complexes and various biological targets, much progress can be made in understanding the mode of action of gold complexes. The low doses on a daily basis for capacity oral administration are the main challenge for a new gold-based drug, in addition to improved cytotoxicity and pharmacological profile. ${ }^{16}$ While developing new gold-based anti-cancer drugs, it is essential to design a drug that would target a specific biological site, resulting in minimizing or no unwanted side effects. ${ }^{17}$ Gold(III) complexes are promising anticancer agents with enhanced stability, having a superior chemotherapeutic index in terms of increased bioavailability, higher cytotoxicity, and promising selectivity associated with lower toxicity towards healthy tissues. Therefore, in vitro screening should be mandatory and should be followed by relevant in vivo studies, which remain the most important evaluation of drug effectiveness in preclinical sites. ${ }^{18}$ In comparison to cisplatin, gold(I) and gold(III) complexes represent a class of compounds that have shown to possess both in vitro and in vivo cytotoxicity, antimicrobial activity and different mode of action, and have received great attention among medicinal inorganic chemists. ${ }^{19,20}$ Anticipated in vivo reduction of gold(III) complexes in the mammalian environment, selection of $\mathrm{N}$-coordinating bidentate and polydentate chelating ligands can satisfactorily stabilize complexes under physiologically relevant conditions. Some complexes possess equal or higher cytotoxicity than cisplatin. ${ }^{21-24}$

The N-coordinating hydrazone and their metal complexes have been investigated earlier demonstrating potential biological application. ${ }^{25-27}$ Various derivatives of Schiff bases based on pyridine, pyrimidine, coumarin, quinoline, benzoxazole, indole, purine, pyrrole, furan, benzofuran and triazoles moieties have been reported earlier for their biological activities, such as antibacterial, antitubercular, anti-inflammatory, anthelmintic, antiviral and antioxidant activities. ${ }^{28,29}$ Gold(III) complexes are the great promise as new pharmacological agents. Therefore, to examine the biological activity of gold(III) complexes, synthesis and characterization of gold(III) complexes have been carried out. The interaction of gold(III) complexes with HS-DNA has been investigated using UV-Vis spectroscopy, viscosity measurement and molecular modeling. The in vitro cytotoxicity and in vivo cytotoxicity of gold(III) complexes examined with a brine shrimp bioassay and $S$. pombe cell, respectively. The antibacterial activity of the synthesized complexes was determined by determining their MIC (minimum inhibitory concentration) values against five different microorganisms.

\section{Materials and Method}

\section{1. Materials and Reagents}

All analytical grade chemicals and solvent were purchased commercially and used as received without further purification. $\mathrm{HAuCl}_{4} \cdot 3 \mathrm{H}_{2} \mathrm{O}$ was purchased from S.D. Fine-Chem Ltd. (India.). 2,2-Dipyridylketone, 2-pyridinecarboxaldehyde, 2-acetylpyridine, phenylhydrazine, benzhydrazide, HS-DNA and EDTA were purchased from Sigma Aldrich Chemical Co. (India). Agarose, Luria Broth (LB), ethidium bromide (EtBr), Tris-acetyl-ESTA (TAE) and bromophenol blue were purchased from Himedia (India). Culture for antibacterial activity Bacillus subtilis (B. subtilis-7193), Staphylococcus aureus (S. aureus-3160), Pseudomonas aeruginosa (P. aeruginosa-1688), Escherichia coli (E. coli-433) and Serratia marcescens (S. marcescens-7103) were purchased from the Institute of Microbial Technology (Chandigarh, India).

\section{2. Physical Measurement}

The ${ }^{1} \mathrm{H}$ and ${ }^{13} \mathrm{C}$ NMR spectra were recorded with a Bruker Avance (400 MHz) spectrometer using deuterated dimethyl sulfoxide and deuterated chloroform solvent. FTIR Shimadzu spectrophotometer was used for IR spectra in the range $4000-300 \mathrm{~cm}^{-1}$. C, $\mathrm{H}$, and $\mathrm{N}$ elemental analysis were performed with a model Perkin-Elmer 240 elemental analyser. Melting points were determined in open capillaries on hermoCal10 melting point apparatus (Analab Scientific Pvt. Ltd, India). The LC-MS spectra were recorded using Thermo scientific mass spectrometer (USA). The electronic spectra of metal complexes were recorded on a UV-160A UV-Vis spectrophotometer, Shimadzu, Kyoto (Japan). The Gouy's method used for magnetic measurement of metal complexes taking mercury tetrathiocyanatocobaltate(II) as the calibrant $\left(\chi_{\mathrm{g}}=16.44 \cdot 10^{-6} \mathrm{cgs}\right.$ units at $20^{\circ} \mathrm{C}$ ), citizen balance. Antibacterial study was carried out by means of laminar air flow cabinet Toshiba, Delhi (India). AlphaDigiDoc ${ }^{\mathrm{TM}}$ RT. Version V.4.0.0 PCImage software, CA (USA) used for the Photo quantization of the DNA cleavage activity.

\subsection{Synthesis and Spectral Characterization of Ligands}

Generally, Schiff base was prepared by condensation of ketone/aldehyde with an amine as per earlier reported literature method. ${ }^{25}$ The reaction mixture of substituted pyridyl ketone $(0.05 \mathrm{~mol})$, substituted hydrazine $(0.05$ mol) and 4-5 drops of conc. $\mathrm{HCl}$ (as a catalyst) in methanol $(15 \mathrm{~mL})$ were refluxed with stirring for $6 \mathrm{~h}$. After completion of the reaction, the reaction mixture was cooled to room temperature and the resulting yellow solids were collected by filtration, washed with ethanol and dried in vaccuo. General reaction scheme for the synthesis of ligand and complexes is shown in Scheme 1.

2,2'-((2-Phenylhydrazono)methylene)dipyridine $\left(\mathrm{L}^{1}\right) \quad$ It has been synthesized according to the above procedure using 2,2'-dipyridyl ketone and phenylhydrazine. Yield: 72\%, m.p. $186{ }^{\circ} \mathrm{C}$, mol. wt. $274.33 \mathrm{~g} \mathrm{~mol}^{-1}$; Anal. Calc. for

Kanthecha et al.: Biological Significance of Hetero-Scaffolds ... 


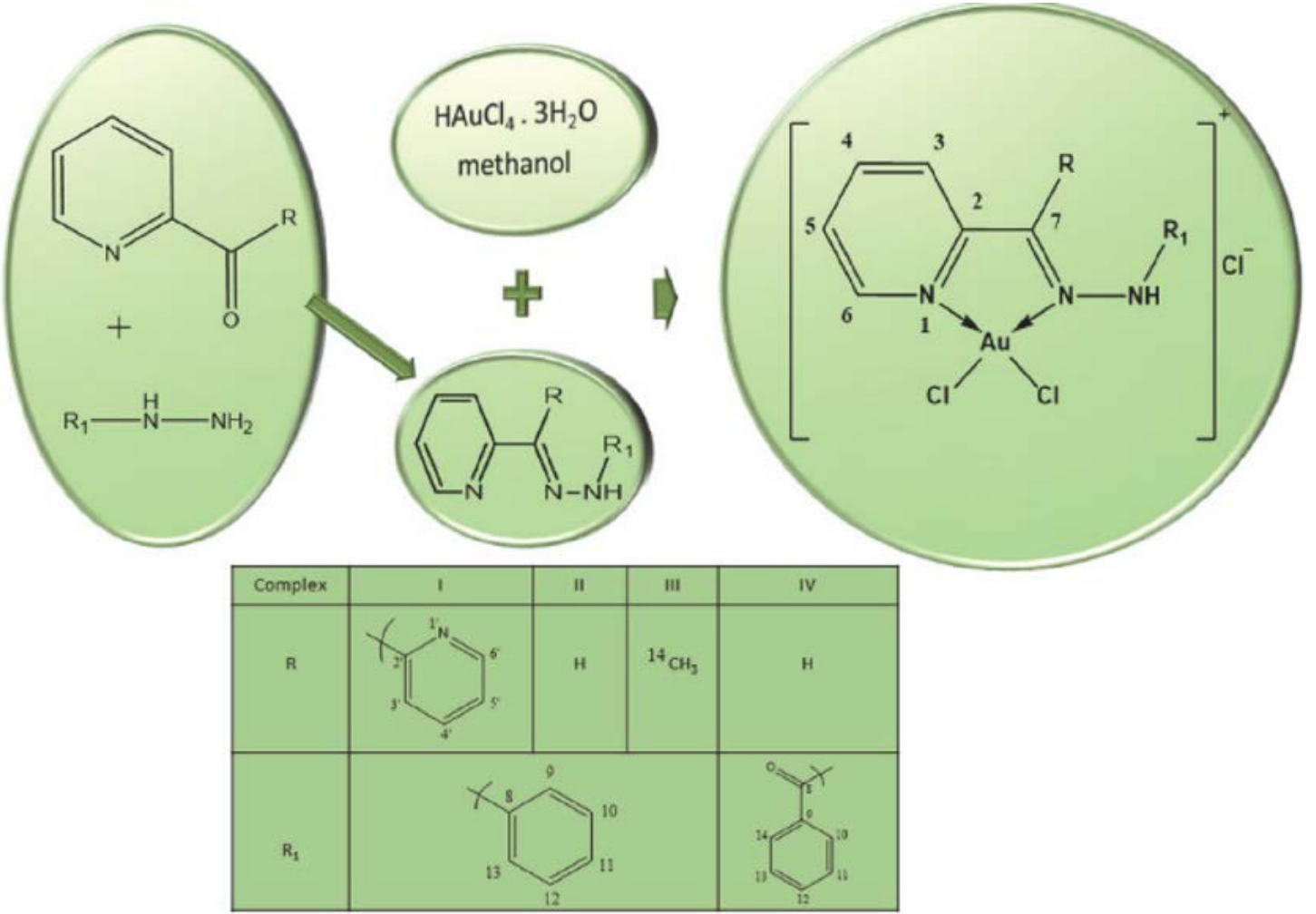

Scheme 1. Synthesis of ligands $\left(\mathrm{L}^{1}-\mathrm{L}^{4}\right)$ and their gold(III) complexes (I-IV).

$\mathrm{C}_{17} \mathrm{H}_{14} \mathrm{~N}_{4}$ : calc. (found) (\%): C, 74.43 (74.23); $\mathrm{H}, 5.14$ (5.17); N, $20.42(20.45) .{ }^{1} \mathrm{H}$ NMR $\left(400 \mathrm{MHz}, \mathrm{CDCl}_{3}-\mathrm{d}_{1}\right) \delta /$ ppm: 6.93-6.98 $\left(1 \mathrm{H}, \mathrm{m}, \mathrm{H}_{11}\right), 7.25-7.36(6 \mathrm{H}, \mathrm{m}$, $\left.\mathrm{H}_{5,5,9,10,12,13}\right), 7.74-7.83\left(3 \mathrm{H}, \mathrm{m}, \mathrm{H}_{3,4,4^{\prime}}\right), 8.02(1 \mathrm{H}, \mathrm{d}, J=8.0$ $\left.\mathrm{Hz}, \mathrm{H}_{3^{\prime}}\right), 8.59\left(1 \mathrm{H}, \mathrm{d}, J=4.8, \mathrm{~Hz}, \mathrm{H}_{6}\right), 8.75(1 \mathrm{H}, \mathrm{d}, J=4.8$ $\left.\mathrm{Hz}, \mathrm{H}_{6}\right), 13.83(1 \mathrm{H}, \mathrm{s}, \mathrm{NH}) .{ }^{13} \mathrm{C}$ NMR $(100 \mathrm{MHz}, \mathrm{CD}-$ $\left.\mathrm{Cl}_{3}-\mathrm{d}_{1}\right)$ 8/ppm: $113.7\left(\mathrm{CH} \mathrm{C}_{9,13}\right), 122.3\left(\mathrm{CH} \mathrm{C} \mathrm{C}_{11}\right), 123.5$ $\left(\mathrm{CH} \mathrm{C}_{3,3^{3}}\right), 125.4\left(\mathrm{CH} \mathrm{C}_{5,5}\right), 129.2\left(\mathrm{CH} \mathrm{C}_{10,12}\right), 136.6(\mathrm{CH}$ $\left.\mathrm{C}_{4,4^{4}}\right), 144.4\left(\mathrm{C}_{\text {quaternary }} \mathrm{C}_{8}\right), 147.9\left(\mathrm{CH} \mathrm{C}_{6,6^{6}}\right), 153.2\left(\mathrm{C}_{\text {quater- }}\right.$ nary $\left.\mathrm{C}_{2,2^{2}}\right), 157.8\left(\mathrm{C}_{\text {quaternary }} \mathrm{C}_{7}\right)$. FT-IR $(\mathrm{KBr}, 4000-400$ $\left.\mathrm{cm}^{-1}\right): 3270 v(\mathrm{~N}-\mathrm{H})_{\text {stretching }} ; 3047 v(\mathrm{C}-\mathrm{H})_{\text {stretching; }} ; 1589$ $v(\mathrm{C}=\mathrm{N}) ; 1427 v(\mathrm{C}=\mathrm{C}) ; 1149 v(\mathrm{C}-\mathrm{N}) ; 794 v(\mathrm{C}-\mathrm{H})_{\text {bending }}$. LC-MS $(\mathrm{m} / z, \%): 275(100)\left[\mathrm{M}^{+}\right]$.

2-((2-Phenylhydrazono)methyl)pyridine $\left(\mathrm{L}^{2}\right)$ It has been synthesized according to the above procedure using 2-pyridinecarboxaldehyde and phenylhydrazine. Yield: $68 \%$, m.p. $195{ }^{\circ} \mathrm{C}$, mol. wt. $197.24 \mathrm{~g} \mathrm{~mol}^{-1}$. Anal. Calc. for $\mathrm{C}_{12} \mathrm{H}_{11} \mathrm{~N}_{3}$ : calc. (found) (\%): C, 73.07 (73.21); H, 5.62 (5.40); N, 21.30 (21.15). ${ }^{1} \mathrm{H}$ NMR (400 MHz, $\left.\mathrm{CDCl}_{3}-\mathrm{d}_{1}\right) \delta /$ ppm: 6.91-6.95 $\left(1 \mathrm{H}, \mathrm{m}, \mathrm{H}_{11}\right), 7.15-7.20\left(3 \mathrm{H}, \mathrm{m}, \mathrm{H}_{5,9,13}\right)$, 7.29-7.34 (2H, m, $\left.\mathrm{H}_{10,12}\right), 7.70\left(1 \mathrm{H}, \mathrm{dd}, J=1.6,6.0 \mathrm{~Hz}, \mathrm{H}_{4}\right)$, $7.82\left(1 \mathrm{H}, \mathrm{s}, \mathrm{H}_{3}\right), 8.02\left(1 \mathrm{H}, \mathrm{d}, J=8.0 \mathrm{~Hz}, \mathrm{H}_{6}\right), 8.18(1 \mathrm{H}, \mathrm{s}$, $\left.\mathrm{H}_{7}\right), 8.55(1 \mathrm{H}, \mathrm{s}, \mathrm{NH}) .{ }^{13} \mathrm{C}$ NMR $\left(100 \mathrm{MHz}, \mathrm{CDCl}_{3}-\mathrm{d}_{1}\right) \delta /$ ppm: $113.0\left(\mathrm{CH} \mathrm{C}_{9,13}\right), 119.6\left(\mathrm{CH} \mathrm{C}_{3}\right), 120.7\left(\mathrm{C}_{11}\right), 122.5$ $\left(\mathrm{CH} \mathrm{C}_{5}\right), 129.3\left(\mathrm{CH} \mathrm{C}_{10,12}\right), 136.2\left(\mathrm{CH} \mathrm{C}_{4}\right), 137.2\left(\mathrm{CH} \mathrm{C}_{7}\right)$, $144.1\left(\mathrm{C}_{\text {quaternary }} \mathrm{C}_{8}\right), 149.0\left(\mathrm{CH} \mathrm{C}_{6}\right), 154.5\left(\mathrm{C}_{\text {quaternary }} \mathrm{C}_{2}\right)$. FT-IR (KBr, $\left.4000-400 \mathrm{~cm}^{-1}\right): 3271 \mathrm{v}(\mathrm{N}-\mathrm{H})_{\text {stretching; }} 3086$
$v(\mathrm{C}-\mathrm{H})_{\text {stretching }} ; 1527 v(\mathrm{C}=\mathrm{N}) ; 1465 v(\mathrm{C}=\mathrm{C}) ; 1149 v(\mathrm{C}-\mathrm{N})$; $750 v(\mathrm{C}-\mathrm{H})_{\text {bending. }}$ LC-MS $(\mathrm{m} / z, \%): 197(100)\left[\mathrm{M}^{+}\right]$.

2-(1-(2-Phenylhydrazono)ethyl)pyridine $\left(\mathrm{L}^{3}\right)$ It has been synthesized according to the above procedure using 2 -acetyl pyridine and phenyl hydrazine. Yield: 75\%, m.p. 166 ${ }^{\circ} \mathrm{C}$, mol. wt. $211.27 \mathrm{~g} \mathrm{~mol}^{-1}$. Anal. Calc. for $\mathrm{C}_{13} \mathrm{H}_{13} \mathrm{~N}_{3}$ : calc. (found) (\%): C, 73.91 (73.85); H, 6.20 (6.30); N, 19.89 (19.93). ${ }^{1} \mathrm{H}$ NMR $\left(400 \mathrm{MHz}, \mathrm{CDCl}_{3}-\mathrm{d}_{1}\right) \delta / \mathrm{ppm}: 2.47(3 \mathrm{H}$, s, $\left.\mathrm{H}_{14}\right) 7.23\left(1 \mathrm{H}, \mathrm{t}, J=6.0 \mathrm{~Hz}, \mathrm{H}_{11}\right), 7.39(1 \mathrm{H}, \mathrm{d} . J=7.2 \mathrm{~Hz}$, $\left.\mathrm{H}_{9}\right), 7.48\left(1 \mathrm{H}, \mathrm{d}, J=6.8, \mathrm{H}_{13}\right), 7.66\left(1 \mathrm{H}, \mathrm{t}, J=8.0 \mathrm{H}_{5}\right), 7.92$ $\left(2 \mathrm{H}, \mathrm{dd}, J=7.2,10.4 \mathrm{~Hz}, \mathrm{H}_{10,12}\right), 8.08(1 \mathrm{H}, \mathrm{t}, J=3.6, \mathrm{~Hz}$, $\left.\mathrm{H}_{4}\right), 8.48\left(2 \mathrm{H}, \mathrm{d}, J=10.4 \mathrm{~Hz}, \mathrm{H}_{3,6}\right), 10.92(1 \mathrm{H}, \mathrm{s}, \mathrm{N}-\mathrm{H}) .{ }^{13} \mathrm{C}$

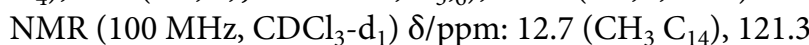
$\left(\mathrm{CH} \mathrm{C}_{9,13}\right), 124.3\left(\mathrm{CH} \mathrm{C}_{3}\right), 127.6\left(\mathrm{CH} \mathrm{C}_{11}\right), 128.6\left(\mathrm{CH} \mathrm{C}_{5}\right)$, $132.1\left(\mathrm{CH} \mathrm{C} \mathrm{C}_{10,12}\right), 132.7\left(\mathrm{C}_{\text {quaternary }} \mathrm{C}_{8}\right), 136.7\left(\mathrm{CH} \mathrm{C} \mathrm{C}_{4}\right)$, $\left.148.3\left(\mathrm{C}_{\text {quaternary }} \mathrm{C}_{7}\right), 149.1(\mathrm{CH} \mathrm{C})_{6}\right), 152.9\left(\mathrm{C}_{\text {quaternary }} \mathrm{C}_{2}\right)$. FT-IR $\left(\mathrm{KBr}, 4000-400 \mathrm{~cm}^{-1}\right): 3255 \mathrm{v}(\mathrm{N}-\mathrm{H})_{\text {stretching; }} 3024$ $v(\mathrm{C}-\mathrm{H})_{\text {stretching; }} ; 2823 v\left(\mathrm{CH}_{3}\right)_{\text {stretching }} ; 1604 v(\mathrm{C}=\mathrm{N}) ; 1450$ $v(\mathrm{C}=\mathrm{C}) ; 1373 v(\mathrm{C}-\mathrm{C}) ; 1172 v(\mathrm{C}-\mathrm{N}) ; 779 v(\mathrm{C}-\mathrm{H})_{\text {bending. }}$. LC-MS $(m / z, \%): 211(100)\left[\mathrm{M}^{+}\right]$.

2-((2-Phenylhydrazono)methyl)pyridine $\left(\mathrm{L}^{4}\right)$ It has been synthesized according to the above procedure using 2-pyridinecarboxaldehyde and benzhydrazide. Yield: $75 \%$, m.p. $142^{\circ} \mathrm{C}$, mol. wt. $225.25 \mathrm{~g} \mathrm{~mol}^{-1}$. Anal. Calc. for $\mathrm{C}_{13} \mathrm{H}_{11} \mathrm{ON}_{3}$ : calc. (found) (\%): C, 69.32 (69.22); H, 4.92 (4.97); N, 18.66 (18.69); O, 7.10 (7.20). ${ }^{1} \mathrm{H}$ NMR (400 MHz, $\left.\mathrm{CDCl}_{3}-\mathrm{d}_{1}\right) \delta /$ 
ppm: $7.21\left(1 \mathrm{H}, \mathrm{t}, J=6.0 \mathrm{~Hz}, \mathrm{H}_{12}\right), 7.34(2 \mathrm{H}, \mathrm{t}, J=6.0 \mathrm{~Hz}$, $\left.\mathrm{H}_{11,13}\right), 7.44\left(1 \mathrm{H}, \mathrm{t}, J=8.0 \mathrm{~Hz}, \mathrm{H}_{5}\right) 7.64(1 \mathrm{H}, \mathrm{t}, J=6.0 \mathrm{~Hz}$, $\left.\mathrm{H}_{4}\right) 7.72-8.05\left(2 \mathrm{H}, \mathrm{m}, \mathrm{H}_{3,6}\right), 8.12\left(1 \mathrm{H}, \mathrm{s}, \mathrm{H}_{7}\right) 8.53(2 \mathrm{H}, \mathrm{d}, J$ $\left.=4.4 \mathrm{~Hz}, \mathrm{H}_{10,14}\right), 11.21(1 \mathrm{H}, \mathrm{s}, \mathrm{N}-\mathrm{H}) .{ }^{13} \mathrm{C}$ NMR $(100 \mathrm{MHz}$,

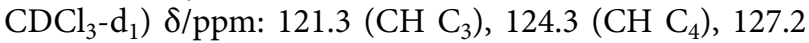
$\left(\mathrm{CH} \mathrm{C}_{10,14}\right), 128.5\left(\mathrm{CH} \mathrm{C}_{11,12}\right), 132.1\left(\mathrm{CH} \mathrm{C}_{13}\right), 132.7\left(\mathrm{C}_{\text {qua- }}\right.$ ternary $\left.\mathrm{C}_{9}\right), 136.7\left(\mathrm{CH} \mathrm{C}_{4}\right), 148.3\left(\mathrm{CH} \mathrm{C}_{7}\right), 149.0(\mathrm{CH} \mathrm{C} 6)$, $152.9\left(\mathrm{C}_{\text {quaternary }} \mathrm{C}_{2}\right), 167.1\left(\mathrm{C}=\mathrm{O} \mathrm{C} \mathrm{C}_{8}\right)$. FT-IR $(\mathrm{KBr}, 4000-$ $\left.400 \mathrm{~cm}^{-1}\right): 3271 v(\mathrm{~N}-\mathrm{H})_{\text {stretching; }} 3032 v(\mathrm{C}-\mathrm{H})_{\text {stretching; }}$ $1689 v(\mathrm{C}=\mathrm{O}) ; 1604 v(\mathrm{C}=\mathrm{N}) ; 1450 v(\mathrm{C}=\mathrm{C}) ; 1165 v(\mathrm{C}-\mathrm{N})$; $794 v(\mathrm{C}-\mathrm{H})_{\text {bending. }}$ LC-MS $(\mathrm{m} / \mathrm{z}, \%): 226(100)\left[\mathrm{M}^{+}\right]$.

\section{4. Synthesis and Spectral Characterization of Gold Complexes}

The prepared methanolic solution of a ligand $\left(\mathrm{L}^{1}-\mathrm{L}^{4}\right)$ $(0.25 \mathrm{mmol})$ was added dropwise into $\mathrm{HAuCl}_{4} \cdot 3 \mathrm{H}_{2} \mathrm{O}(0.25$ $\mathrm{mmol})$ in methanol $(5 \mathrm{~mL})$ with stirring at room temperature for $10 \mathrm{~min}$ and the reaction mixture was refluxed for further $2 \mathrm{~h}$. After complete complexation orange precipitate has appeared and filtered, washed with diethyl ether and dried in vaccuo.

$\left[\mathrm{Au}\left(\mathrm{L}^{1}\right) \mathrm{Cl}_{2}\right] \mathrm{Cl}$ (I) It has been synthesized using 2,2'-((2-phenylhydrazono)methylene)dipyridine $\left(\mathrm{L}^{1}\right)$. Yield: $59 \%$, m.p. $>250{ }^{\circ} \mathrm{C}$, mol. wt.: $577.64 \mathrm{~g} \mathrm{~mol}^{-1}$; Anal. Calc. for $\mathrm{C}_{17} \mathrm{H}_{14} \mathrm{AuCl}_{3} \mathrm{~N}_{4}$ : calc. (found) (\%): C, 35.35 (36.76); H, 2.44 (2.24); N, 9.70 (10.11). ${ }^{1} \mathrm{H}$ NMR (400 MHz, DMSO-d $\left.{ }_{6}\right) \delta /$ ppm: $7.69\left(1 \mathrm{H}, \mathrm{t}, J=6.0 \mathrm{~Hz}, \mathrm{H}_{11}\right), 7.89$ $\left(3 \mathrm{H}, \mathrm{d}, J=5.6 \mathrm{~Hz}, \mathrm{H}_{3,10,12}\right), 8.01\left(2 \mathrm{H}, \mathrm{d}, J=7.6 \mathrm{~Hz}, \mathrm{H}_{9,13}\right)$, $8.05\left(1 \mathrm{H}, \mathrm{d}, J=7.2 \mathrm{~Hz}, \mathrm{H}_{3}\right), 8.12-8.16\left(1 \mathrm{H}, \mathrm{m}, \mathrm{H}_{5}\right), 8.38$ $\left(2 \mathrm{H}, \mathrm{dd}, J=8.0,9.2 \mathrm{~Hz}, \mathrm{H}_{5,6^{\prime}}\right), 8.93\left(1 \mathrm{H}, \mathrm{d}, J=4.8 \mathrm{~Hz}, \mathrm{H}_{4^{\prime}}\right)$, $9.30\left(1 \mathrm{H}, \mathrm{d}, J=8.8 \mathrm{~Hz}, \mathrm{H}_{4}\right), 9.35\left(1 \mathrm{H}, \mathrm{d}, J=7.2 \mathrm{~Hz}, \mathrm{H}_{6}\right)$, $12.60(1 \mathrm{H}, \mathrm{s}, \mathrm{N}-\mathrm{H}) .{ }^{13} \mathrm{C}$ NMR $\left(100 \mathrm{MHz}, \mathrm{DMSO}-\mathrm{d}_{6}\right) \delta /$ ppm: $122.1\left(\mathrm{CH} \mathrm{C}_{9,13}\right), 123.0\left(\mathrm{CH} \mathrm{C}_{11}\right), 124.3\left(\mathrm{CH} \mathrm{C} 3^{\prime}\right)$, 125.5 $\left(\mathrm{CH} \mathrm{C}_{5}\right), 126.0\left(\mathrm{CH} \mathrm{C}_{5}\right), 127.8\left(\mathrm{CH} \mathrm{C}_{10,12}\right), 131.2(\mathrm{CH}$ $\left.\mathrm{C}_{3}\right), 133.3\left(\mathrm{CH} \mathrm{C}_{4}\right), 133.6\left(\mathrm{C}_{\text {quaternary }} \mathrm{C}_{8}\right), 134.5\left(\mathrm{C}_{\text {quaternary }}\right.$ $\left.\mathrm{C}_{2}\right), 135.9\left(\mathrm{CH} \mathrm{C}_{6}\right), 138.8\left(\mathrm{CH} \mathrm{C}_{4}\right), 140.2\left(\mathrm{C}_{\text {quaternary }} \mathrm{C}_{7}\right)$, $147.8\left(\mathrm{C}_{\text {quaternary }} \mathrm{C}_{2}\right), 150.7\left(\mathrm{CH} \mathrm{C}_{6}\right)$. FT-IR $(\mathrm{KBr}, 4000-400$ $\left.\mathrm{cm}^{-1}\right): 3271 v(\mathrm{~N}-\mathrm{H})_{\text {stretching }} ; 3062 v(\mathrm{C}-\mathrm{H})_{\text {stretching; }} ; 1581$ $v(\mathrm{C}=\mathrm{N}) ; 1481 v(\mathrm{C}=\mathrm{C}) ; 1126 v(\mathrm{C}-\mathrm{N}) ; 825 v(\mathrm{C}-\mathrm{H})_{\text {bending; }}$; $416 v(\mathrm{Au}-\mathrm{N}) ; 347 v(\mathrm{Au}-\mathrm{Cl})$. LC-MS ( $\mathrm{m} / z, \%): 541(100)$ $\left[\mathrm{M}^{+}\right]$.

$\left[\mathrm{Au}\left(\mathrm{L}^{2}\right) \mathrm{Cl}_{2}\right] \mathrm{Cl}$ (II) It has been synthesized using 2-(1-(2-phenylhydrazono)ethyl)pyridine $\left(\mathrm{L}^{2}\right)$. Yield: $62 \%$, m.p. $>250{ }^{\circ} \mathrm{C}$, mol. wt. $465.11 \mathrm{~g} \mathrm{~mol}^{-1}$; Anal. Calc. for $\mathrm{C}_{12} \mathrm{H}_{11} \mathrm{AuCl}_{2} \mathrm{~N}_{3}$ : calc. (found) (\%): C, 30.99 (30.95); $\mathrm{H}$, 2.38 (2.42); N, 9.03 (8.89). ${ }^{1} \mathrm{H}$ NMR (400 MHz, DMSO-d 6 ) $\delta / \mathrm{ppm}: 7.15\left(1 \mathrm{H}, \mathrm{d}, J=4.8 \mathrm{~Hz}, \mathrm{H}_{11}\right), 7.27(1 \mathrm{H}, \mathrm{d}, J=5.6 \mathrm{~Hz}$, $\left.\mathrm{H}_{3}\right), 7.40\left(1 \mathrm{H}, \mathrm{d}, J=5.2 \mathrm{~Hz}, \mathrm{H}_{4}\right), 7.50-7.67\left(3 \mathrm{H}, \mathrm{m}, \mathrm{H}_{7,9,13}\right)$, 7.92-8.22 (3H, m, $\left.\mathrm{H}_{6,10,12}\right), 8.62-8.72\left(1 \mathrm{H}, \mathrm{m}, \mathrm{H}_{5}\right), 10.63$ $(1 \mathrm{H}, \mathrm{s}, \mathrm{NH}) .{ }^{13} \mathrm{C}$ NMR $(100 \mathrm{MHz}$, DMSO-d 6 ) $\delta / \mathrm{ppm}:$ $122.8\left(\mathrm{CH} \mathrm{C}_{9,13}\right), 127.9\left(\mathrm{CH} \mathrm{C}_{11}\right), 128.9\left(\mathrm{CH} \mathrm{C}_{3}\right), 129.7$ $\left(\mathrm{CH} \mathrm{C}_{10,12}\right), 131.3\left(\mathrm{CH} \mathrm{C}_{5}\right), 132.6\left(\mathrm{CH} \mathrm{C}_{6}\right), 133.3\left(\mathrm{C}_{\text {quater- }}\right.$ nary $\left.\mathrm{C}_{8}\right), 138.3\left(\mathrm{CH} \mathrm{C}_{7}\right), 146.0\left(\mathrm{CH} \mathrm{C}_{4}\right), 149.1\left(\mathrm{C}_{\text {quaternary }}\right.$
$\left.\mathrm{C}_{2}\right)$. FT-IR $\left(\mathrm{KBr}, 4000-400 \mathrm{~cm}^{-1}\right): 3290 v(\mathrm{~N}-\mathrm{H})_{\text {stretching; }}$; $3055 v(\mathrm{C}-\mathrm{H})_{\text {stretching; }} 1597 v(\mathrm{C}=\mathrm{N}) ; 1427 v(\mathrm{C}=\mathrm{C}) ; 1134$ $v(\mathrm{C}-\mathrm{N}) ; 748 v(\mathrm{C}-\mathrm{H})_{\text {bending; }} ; 509 v(\mathrm{Au}-\mathrm{N}) ; 354 v(\mathrm{Au}-\mathrm{Cl})$. LC-MS ( $m / z, \%): 430(100)\left[\mathrm{M}^{+}\right]$.

$\left[\mathrm{Au}\left(\mathrm{L}^{3}\right) \mathrm{Cl}_{2}\right] \mathrm{Cl}$ (III) It has been synthesized using $N^{\prime}$ (di(pyridin-2-yl)methylene)benzohydrazide $\left(\mathrm{L}^{3}\right)$. Yield: $57 \%$, m.p. $>250{ }^{\circ} \mathrm{C}$, mol. wt. $479.13 \mathrm{~g} \mathrm{~mol}^{-1}$; Anal. Calc. for $\mathrm{C}_{13} \mathrm{H}_{13} \mathrm{AuCl}_{2} \mathrm{~N}_{3}$ : calc. (found) (\%): C, 32.59 (32.43); $\mathrm{H}$, 2.73 (2.81); N, 8.77 (8.85). ${ }^{1} \mathrm{H}$ NMR (400 MHz, DMSO-d ${ }_{6}$ ) $\delta / \mathrm{ppm}: 2.38\left(3 \mathrm{H}, \mathrm{s}, \mathrm{H}_{14}\right), 6.92\left(1 \mathrm{H}, \mathrm{t}, J=7.2 \mathrm{~Hz}, \mathrm{H}_{11}\right), 7.05$ $\left(1 \mathrm{H}, \mathrm{d}, J=8.0 \mathrm{~Hz}, \mathrm{H}_{5}\right), 7.18\left(1 \mathrm{H}, \mathrm{s}, \mathrm{H}_{3}\right), 7.31(2 \mathrm{H}, \mathrm{t}, J=6.8$ $\left.\mathrm{Hz}, \mathrm{H}_{10,12}\right), 7.51\left(2 \mathrm{H}, \mathrm{d}, J=7.6 \mathrm{~Hz}, \mathrm{H}_{9,13}\right), 8.24(1 \mathrm{H}, \mathrm{t}, J=$ $4.0 \mathrm{~Hz}, \mathrm{H} 4), 8.67\left(1 \mathrm{H}, \mathrm{d}, J=5.6 \mathrm{~Hz}, \mathrm{H}_{6}\right), 10.18(1 \mathrm{H}, \mathrm{s}$, $\mathrm{N}-\mathrm{H}) .{ }^{13} \mathrm{C}$ NMR $\left(100 \mathrm{MHz}, \mathrm{DMSO}-\mathrm{d}_{6}\right) \delta / \mathrm{ppm}: 12.9\left(\mathrm{CH}_{3}\right.$ $\left.\mathrm{C}_{14}\right), 114.4\left(\mathrm{CH} \mathrm{C}_{9,13}\right), 123.6\left(\mathrm{CH} \mathrm{C}_{11}\right), 124.2\left(\mathrm{CH} \mathrm{C}_{5}\right)$, $127.36\left(\mathrm{CH} \mathrm{C}_{10,12}\right), 132.0\left(\mathrm{CH} \mathrm{C}_{3}\right), 133.6\left(\mathrm{C}_{\text {quaternary }} \mathrm{C}_{7}\right)$, $137.3\left(\mathrm{CH} \mathrm{C}_{6}\right), 147.4\left(\mathrm{C}_{\text {quaternary }} \mathrm{C}_{8}\right), 148.2\left(\mathrm{CH} \mathrm{C}_{4}\right), 156.1$ $\left(\mathrm{C}_{\text {quaternary }} \mathrm{C}_{2}\right)$. FT-IR $\left(\mathrm{KBr}, 4000-400 \mathrm{~cm}^{-1}\right): 3286 v(\mathrm{~N}-\mathrm{H})$ stretching; $3001 v(\mathrm{C}-\mathrm{H})_{\text {stretching; }} ; 2893 v\left(\mathrm{CH}_{3}\right)_{\text {stretching; }} ; 1604$ $v(\mathrm{C}=\mathrm{N}) ; 1494 v(\mathrm{C}=\mathrm{C}) ; 1435 v(\mathrm{C}-\mathrm{C}) ; 1157 v(\mathrm{C}-\mathrm{N}) ; 825$ $v(\mathrm{C}-\mathrm{H})_{\text {bendin }} ; 510 v(\mathrm{Au}-\mathrm{N}) ; 339 v(\mathrm{Au}-\mathrm{Cl})$. LC-MS $(\mathrm{m} / z$, $\%): 443(100)\left[\mathrm{M}^{+}\right]$.

$\left[\mathrm{Au}\left(\mathrm{L}^{4}\right) \mathrm{Cl}_{2}\right] \mathrm{Cl}$ (IV) It has been synthesized using 2-((2-phenylhydrazono)methyl)pyridine $\left(\mathrm{L}^{4}\right)$. Yield: 55\%, m.p. $>250{ }^{\circ} \mathrm{C}$, mol. wt. $493.12 \mathrm{~g} \mathrm{~mol}{ }^{-1}$; Anal. Calc. for $\mathrm{C}_{13} \mathrm{H}_{11} \mathrm{AuCl}_{2} \mathrm{~N}_{3} \mathrm{O}$ : calc. (found) (\%): C, 31.66 (31.50); $\mathrm{H}$, 2.25 (2.18); N, 8.52 (8.90). ${ }^{1} \mathrm{H}$ NMR $\left(400 \mathrm{MHz}, \mathrm{DMSO}^{-} \mathrm{d}_{6}\right)$ $\delta / \mathrm{ppm}: 7.07\left(1 \mathrm{H}, \mathrm{d}, J=2.4 \mathrm{~Hz}, \mathrm{H}_{12}\right), 7.20(1 \mathrm{H}, \mathrm{d}, J=2.0 \mathrm{~Hz}$, $\left.\mathrm{H}_{3}\right), 7.33\left(1 \mathrm{H}, \mathrm{s}, \mathrm{H}_{7}\right), 7.52\left(2 \mathrm{H}, \mathrm{t}, J=7.6 \mathrm{~Hz}, \mathrm{H}_{11,13}\right), 7.60$ $\left(1 \mathrm{H}, \mathrm{t}, J=4.4 \mathrm{~Hz}, \mathrm{H}_{5}\right), 7.66\left(1 \mathrm{H}, \mathrm{t}, J=2.8 \mathrm{~Hz} \mathrm{H}_{4}\right), 7.93(2 \mathrm{H}$, d, $\left.J=11.6 \mathrm{~Hz}, \mathrm{H}_{10,14}\right), 8.13\left(1 \mathrm{H}, \mathrm{dd}, J=7.6,12 \mathrm{~Hz}, \mathrm{H}_{6}\right)$, $11.50(1 \mathrm{H}, \mathrm{s}, \mathrm{N}-\mathrm{H}) .{ }^{13} \mathrm{C}$ NMR $\left(100 \mathrm{MHz}, \mathrm{DMSO}_{-} \mathrm{d}_{6}\right) \delta /$ ppm: $122.8\left(\mathrm{CH} \mathrm{C}_{10,14}\right), 127.9\left(\mathrm{CH} \mathrm{C}_{5}\right), 128.2\left(\mathrm{CH} \mathrm{C}_{11,13}\right)$, 128.9 $\left(\mathrm{CH} \mathrm{C}_{3}\right), 129.7\left(\mathrm{CH} \mathrm{C}_{12}\right), 130.0\left(\mathrm{CH} \mathrm{C}_{6}\right), 132.3(\mathrm{CH}$ $\left.\mathrm{C}_{4}\right), 133.0\left(\mathrm{C}_{\text {quaternary }} \mathrm{C}_{9}\right), 138.4\left(\mathrm{CH} \mathrm{C}_{7}\right), 149.1\left(\mathrm{C}_{\text {quaternary }}\right.$ $\left.\mathrm{C}_{2}\right), 165.9\left(\mathrm{C}=\mathrm{O} \mathrm{C} \mathrm{C}_{8}\right)$. FT-IR $\left(\mathrm{KBr}, 4000-400 \mathrm{~cm}^{-1}\right): 3270$ $v(\mathrm{~N}-\mathrm{H})_{\text {stretching }} ; 3093 v(\mathrm{C}-\mathrm{H})_{\text {stretching }} ; 1720 v(\mathrm{C}=\mathrm{O}) ; 1597$ $v(\mathrm{C}=\mathrm{N}) ; 1481 v(\mathrm{C}=\mathrm{C}) ; 1157 v(\mathrm{C}-\mathrm{N}) ; 748 v(\mathrm{C}-\mathrm{H})_{\text {bending; }}$; $417 v(\mathrm{Au}-\mathrm{N}) ; 347 v(\mathrm{Au}-\mathrm{Cl})$. LC-MS $(\mathrm{m} / z, \%): 458(100)$ $\left[\mathrm{M}^{+}\right]$.

\section{Biological Screening of Synthesized Compounds}

\section{1. UV-Vis Absorbance Titration}

Binding mode and interaction strength of DNA with metal complexes have been examined effectively by electronic absorption spectra (UV-Vis absorbance titration) using Herring Sperm DNA (HS-DNA) with $\varepsilon=12858 \mathrm{dm}^{3}$ $\mathrm{mol}^{-1} \mathrm{~cm}^{-1}$ in phosphate buffer solution ( $\mathrm{pH}$ 7.2). The stock solutions of the complexes were prepared in DMSO. The absorption titration has been performed by the con- 
centration of complex keeping constant $(20 \mu \mathrm{M})$ and continuous adding the volume of DNA $(100 \mu \mathrm{L})$, and incubated for $10 \mathrm{~min}$ at room temperature. By using absorption spectral titration data $K_{\mathrm{b}}$ value have been determined from the ratio of the slope to intercept from the plot of [DNA]/ $\left(\varepsilon_{\mathrm{a}}-\varepsilon_{\mathrm{f}}\right)$ versus $[\mathrm{DNA}] .^{30}$

\section{2. Viscosity Measurement}

An Ubbelohde viscometer maintained at a constant temperature of $27 \pm 0.1{ }^{\circ} \mathrm{C}$ in a thermostatic jacket. It was used to measure the flow time of HS-DNA in phosphate buffer ( $\mathrm{pH} 7.2)$ with a digital stopwatch. Flow time measurements of each compound were carried out three times to calculate average flow time. Data were presented as relative specific viscosity $\left(\left(\eta / \eta_{0}\right)^{1 / 3}\right)$ versus binding ratio ([Drug] $] /[\mathrm{DNA}],{ }^{31}$ where $\eta$ and $\eta_{0}$ is the viscosity of DNA in the presence of complex and viscosity of DNA alone, respectively. Viscosity values have been calculated from the observed flow time of DNA containing solutions ( $t>100 \mathrm{~s}$ ), corrected for the flow time of buffer alone $\left(t_{0}\right), \eta \propto\left(t-t_{0}\right) .^{32}$

\section{3. Molecular Docking Study}

The interaction between DNA and complexes at the molecular level were studied by advanced computational technique. The rigid molecular docking study has been executed using HEX 8.0 software to conclude the orientation of the $\mathrm{Au}(\mathrm{III})$ complexes binding to DNA. The most stable configuration was selected as the input for investigation. Mole file of coordinates of metal complexes was prepared for optimized structure and was rehabilitated to .pdb format using CHIMERA 1.5.1 software. HS-DNA used in the experimental, the structure of the DNA of sequence (5'-d(CGCGAATTCGCG)-3') ${ }_{2}$ (PDB id: 1BNA, a familiar sequence used in oligodeoxynucleotide study) obtained from the Protein Data Bank (http://www.rcsb.org/pdb). All calculations were carried out on an Intel CORE i5, 2.20 $\mathrm{GHz}$ based machine running MS Windows 8.164 bit as the operating system. The default parameters were used for the docking calculation with correlation type shape only, FFT mode at the 3D level, grid dimension of 6 with receptor range 180 and ligand range 180 with twist range 360 and distance range 40.33

\section{4. In vitro Cytotoxicity}

The toxicity of bioactive compounds were carried out using brine shrimp (Artemia cysts) lethality bioassay. ${ }^{34}$ Brine shrimp (Artemia cysts) eggs were hatched in a shallow rectangular plastic dish $(22 \times 32 \mathrm{~cm})$, filled with artificial seawater, which was prepared by dissolving sea salt in double distilled water. An unequal partition was made in the plastic dish with the help of a perforated device. Approximately $50 \mathrm{mg}$ of eggs were sprinkled into the large compartment and was opened to ordinary light. After two days, nauplii were collected by a pipette from the lighted side. A sample of the test compound was prepared by dissolving $10 \mathrm{mg}$ of each compound in $10 \mathrm{~mL}$ of DMSO. From these stock solutions, solutions were transfer to 18 vials to make final concentration $2,4,8,12,16$, and $20 \mathrm{mg}$ $\mathrm{mL}^{-1}$ (three sets for each dilutions were used for each test sample and mean of three sets was used for $\mathrm{LC}_{50}$ calculation), and three vials were kept as control having same amount of DMSO only. When the nauplii were ready, $1 \mathrm{~mL}$ of seawater and 10 shrimps were added to each vial, and the volume was adjusted with seawater to $2.5 \mathrm{~mL}$ per vial. After $24 \mathrm{~h}$, the number of survivors was counted. Data were analyzed by simple logit method to determine the $\mathrm{LC}_{50}$ values, in which log of concentration of samples were plotted against percentage of mortality of nauplii.

\section{5. Cellular Level Cytotoxicity Assay}

Eukaryotic Schizosaccharomyces pombe was an important organism for the study of effects of the metal complexes at cellular level (cytotoxicity) to the DNA damage (genotoxicity). S. pombe were grown in liquid yeast extract media in $150 \mathrm{~mL}$ Erlenmeyer flask containing $50 \mathrm{~mL}$ of yeast extract media. To acquire the enough growth of $S$. pombe, flask was incubated at $30^{\circ} \mathrm{C}$ on shaker at $150 \mathrm{rpm}$ ( 24 to $30 \mathrm{~h}$ ). Then the cell culture was treated with synthesized ligands, complexes and DMSO (as control) at different concentrations $\left(2,4,6,8,10 \mathrm{mg} \mathrm{mL}^{-1}\right)$, further allowed to growth for 16-18 h. Next day, the treated and control cells were centrifuged at $10,000 \mathrm{rpm}$ for $10 \mathrm{~min}$ to remove the media and wash the cells with phosphate buffer saline (PBS) three times. Cells were resuspend in $500 \mu \mathrm{L}$ of PBS. Take the $10 \mu \mathrm{L}$ of cells suspension and $10 \mu \mathrm{L} 0.4 \%$ trypan blue dye in vial and incubate for $5 \mathrm{~min}$. at room temperature, then $10 \mu \mathrm{L}$ from the above mixture were put on glass slide and observed in a microscope (40X). The treated cells were observed as colourless or blue in colour, dead cells permitting the entry of trypan blue dye in the cells and appear as blue, whereas the live cells resisted the entry of dye and appear as colourless. Percentage viability was counted in triplicate where number of dead cells and number of live cells were counted in three microscopic fields and calculated average percentage of live cells. ${ }^{35}$

\section{6. Antibacterial Activity}

All of the newly synthesized gold(III) complexes (IIV) were screened for their antibacterial activity using Staphylococcus aureus, Bacillus subtilis, Serratia marcescens, Pseudomonas aeruginosa and Escherichia coli micro-organisms. The broth dilution technique has been used to determine the bactericidal effect by minimum inhibitory concentration (MIC) in terms of $\mu \mathrm{M}$. MIC is the lowest concentration that prevents the microbial growth incubated at $37 \pm 1{ }^{\circ} \mathrm{C}$ for $24 \mathrm{~h}$. MIC was determined in liquid media containing $0.2-3500 \mu \mathrm{M}$ of the tested compound. A precul- 
ture of bacteria was grown in Luria broth overnight at $37^{\circ} \mathrm{C}$. First culture was used as a control to examine normal growth and second culture $20 \mu \mathrm{L}$ of the bacteria and compound at the desired concentration were added to monitor bacterial growth by measuring turbidity of the culture after $18 \mathrm{~h}$. If a certain concentration of a compound inhibit bacterial growth, half of the concentration of the compound was tested. This procedure was carried out up to the concentration that inhibited the growth of bacteria. All equipment and culture media were sterilized.

\section{7. DNA Cleavage Study}

Effect of compounds on the integrity of $S$. pombe cell's DNA were studied by agarose gel electrophoresis. The $S$. pombe cells were grown and treated as in cellular level cytotoxicity assay. After treatment, cells were harvested by centrifugation $10,000 \mathrm{rpm}$ for $10 \mathrm{~min}$ than washed with PBS three times. Cells were resuspended in $0.5 \mu \mathrm{L}$ of distilled water after removing supernatant, then transferred to screw-cap microfuge tube containing $0.2 \mathrm{~mL}$ of lysis buffer ( $2 \%$ Triton X-100, $1 \%$ sodium dodecyl sulphate, 100 $\mathrm{mM} \mathrm{NaCl}, 10 \mathrm{mM}$ Tris-HCl (pH 8.0) and $1 \mathrm{mM}$ EDTA ( $\mathrm{pH}$ 8.0)), $0.2 \mathrm{~mL}$ mixture of phenol/chloroform/isoamyl alcohol (25:24:1) and glass beads. Vortex the screw-cap having cells to break the cells for $1 \mathrm{~min}$ to 3-4 times with alternating cooling. It was centrifuged for $5 \mathrm{~min}$ and transferred the upper aqueous layer to other tube followed by the addition of $3 \mathrm{M}$ sodium acetate (1/10 volume) and $100 \%$ ethanol (2.5 volume) and centrifuged again for 5 min. Pellet were collected and wash with $70 \%$ ethanol. Then 20-30 $\mu \mathrm{L}$ Tris-EDTA buffer was added in the vail contain pellet. Agarose gel electrophoresis were carried out using $0.8 \%$ agarose, Tris-acetate-EDTA buffer and staining with ethidium bromide $\left(0.5 \mathrm{mg} \mathrm{mL}^{-1}\right)$ at $100 \mathrm{~V}$. Image was captured by a CCD camera and Alpha Digi Doc system was used for analysing gel. ${ }^{36}$

\section{Result and Discussion}

\section{1. NMR and IR Spectra of Synthesized Compound}

The NMR and IR spectra of the synthesized ligands and gold(III) complexes are represented in supplementary material and data are shown in the experimental section. The ${ }^{1} \mathrm{H}$ NMR spectra of compounds show a downfield shift of the C-6 proton next to the coordinating nitrogen from 0.19 to $0.76 \mathrm{ppm}$, this indicates that the ligand coordinate to the gold ion. The $\delta \mathrm{ppm}$ values for the NH hydrogen in complexes I and III show upfield shift by 1.23 and $0.76 \mathrm{ppm}$, whereas complexes II and IV show downfield shift from 2.08 to $0.3 \mathrm{ppm}$, respectively, due to different environment near to $\mathrm{N}-\mathrm{H}$ hydrogen. The $\delta$ values of phenyl ring protons in the ligands $\left(\mathrm{L}^{1}-\mathrm{L}^{4}\right)$ are observed at
6.92-7.35 ppm and after the coordination with gold metal ion they are shifted to $6.94-8.61 \mathrm{ppm}$. Infrared spectra of the ligands show intense band for $v(\mathrm{C}=\mathrm{N})_{a r}, v(\mathrm{C}-\mathrm{N})_{\mathrm{ar}}$, $v(\mathrm{C}-\mathrm{H})_{\mathrm{ar}}, v(\mathrm{C}=\mathrm{C})_{\mathrm{ar}}, v(\mathrm{~N}-\mathrm{H})$ at $1527-1604 \mathrm{~cm}^{-1}, 1149$ $1172 \mathrm{~cm}^{-1}, 3024-3086 \mathrm{~cm}^{-1}, 1427-1465 \mathrm{~cm}^{-1}$ and 3255$3271 \mathrm{~cm}^{-1}$, respectively. In gold(III) complexes band are slightly shifted for $v(\mathrm{C}=\mathrm{N})_{\mathrm{ar}}, v(\mathrm{C}-\mathrm{N})_{\mathrm{ar}}, v(\mathrm{C}-\mathrm{H})_{\mathrm{ar}}, v(\mathrm{C}=\mathrm{C})$ ar, $v(\mathrm{~N}-\mathrm{H})$ at $1581-1604 \mathrm{~cm}^{-1}, 1126-1157 \mathrm{~cm}^{-1}, 3001-$ $3093 \mathrm{~cm}^{-1}, 1427-1481 \mathrm{~cm}^{-1}, 3270-3290 \mathrm{~cm}^{-1}$, respectively and intense band for $v(\mathrm{Au}-\mathrm{N})$ appear in the region 416$510 \mathrm{~cm}^{-1}$ and $v(\mathrm{Au}-\mathrm{Cl})$ in the region $339-354 \mathrm{~cm}^{-1} \cdot{ }^{37} \mathrm{Ac}-$ cording to these data we can conclude that ligands coordinate to the gold ion.

\section{2. Magnetic Moments, Electronic Spectra and Conductance Measurements}

Magnetic moments measurement of gold(III) complexes has been carried out at room temperature. The $\mu_{\text {eff }}$ value of gold(III) complexes are zero B.M, which corresponds to all paired electron in low-spin $5 \mathrm{~d}^{8}$ configuration and confirms that gold complexes have +3 oxidation states with low-spin $\mathrm{t}_{2 \mathrm{~g}}{ }^{6} \mathrm{e}_{\mathrm{g}}{ }^{2}$ configuration. The electronic spectra (Fig. 1) of all the complexes in DMSO exhibit intra-ligand charge transfer band $\left(\pi-\pi^{*}\right)$ and MLCT band $\left(n-\pi^{*}\right)$ at 254-274 nm and 290-327 nm, respectively. The molar conductivity value of the gold(III) complexes are in the range of $83-102 \mathrm{~cm}^{2} \Omega^{-1} \mathrm{~mol}^{-1}$ at room temperature, which suggests the electrolytic nature of metal complexes having one counter ion outside the coordination sphere. So, we conclude that all synthesized gold(III) complexes having chlorine as counter ion and square-planar geometry. The single-crystal structure of similar square-planer gold(III) with bidentate $\mathrm{N}, \mathrm{N} / \mathrm{N}, \mathrm{C}$ ligation have also been reported. ${ }^{38-40}$

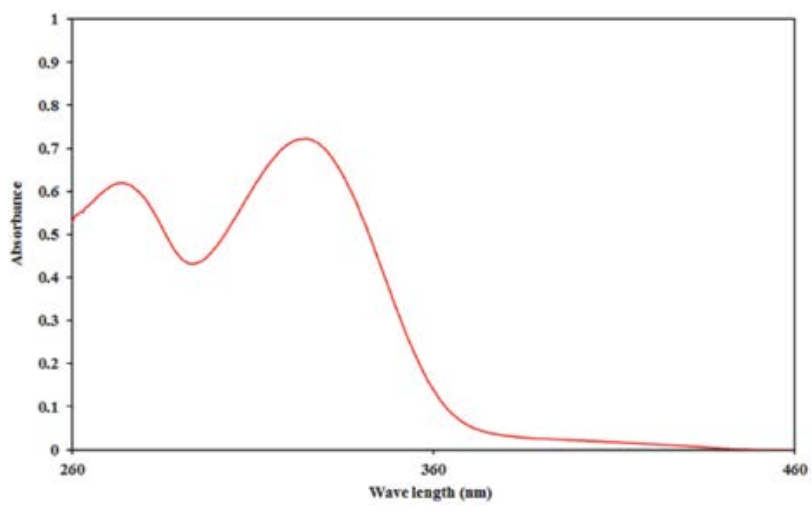

Figure 1. UV absorption spectra of representative complex $\mathbf{I}$ in DMSO

\section{3. Binding Behaviour of Complex with HS DNA}

Electronic absorption titration is one of the technique to investigate the binding mode of metal complexes 
with DNA and provides intrinsic DNA binding constants $\left(K_{\mathrm{b}}\right)$ using Herring Sperm DNA (HS-DNA) with $\varepsilon=12858$ $\mathrm{dm}^{3} \mathrm{~mol}^{-1} \mathrm{~cm}^{-1}$ in phosphate buffer solution ( $\mathrm{pH}$ 7.2). Strong stacking interaction among chromophore of complex and DNA base pair result in hypochromic shift and red shift (bathochromic shift) in absorption spectra which generally indicate that intercalation binding. ${ }^{41,42}$ The increase in DNA volume leads to hypochromic shift with bathochromic shift (Fig. 2), and concludes the intercalation mode of binding between compounds and DNA base pair. The plot of [DNA] $/\left(\varepsilon_{\mathrm{a}}-\varepsilon_{\mathrm{f}}\right)$ versus [DNA] were analyzed to evaluate $K_{b}$ determined from the spectroscopic titration data from the following equation:

$$
\frac{[D N A]}{[\varepsilon a-\varepsilon f]}=\frac{[D N A]}{[\varepsilon b-\varepsilon f]}+\frac{1}{K b(\varepsilon b-\varepsilon f)}
$$

$K_{b}$ values for gold(III) complexes I-IV (Fig. 2) are $3.05 \cdot 10^{5} \mathrm{M}^{-1}, 3.44 \cdot 10^{5} \mathrm{M}^{-1}, 1.08 \cdot 10^{5} \mathrm{M}^{-1}$ and $2.75 \cdot 10^{5}$ $\mathrm{M}^{-1}$, respectively. Complex II shows higher binding affinity towards HS-DNA in comparison to other complex.

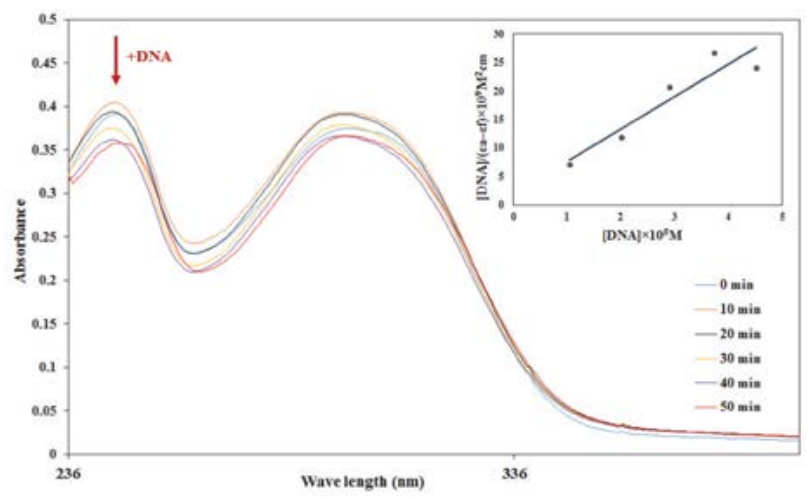

Figure 2. Absorption spectra of complex I with increasing concentration of HS-DNA after incubation for $10 \mathrm{~min}$ for each addition at $37^{\circ} \mathrm{C}$ in phosphate buffer ( $\mathrm{pH}$ 7.2). Inset: Plots of [DNA]/( $\left.\varepsilon_{\mathrm{a}}-\varepsilon_{\mathrm{f}}\right)$ versus [DNA] for the titration of DNA with gold(III) complexes.

\section{4. Hydrodynamic Volume Measurement}

Viscosity measurement is the most useful study of DNA interaction in the absence of X-ray crystallographic data. ${ }^{31}$ Interaction of complex moiety with DNA alters the length of DNA duplex and directly influences on the intrinsic viscosity. The intrinsic viscosity depends on the mode of interaction with concentration of complexes. This phenomenon may be explained by insertion of the complex between base pairs, leading to an increase in the separation of base pairs at the intercalation sites and thus an increase in overall DNA length. ${ }^{43}$ The increase in viscosity confirms that the $\mathrm{Au}(\mathrm{III})$ complexes are bound to HSDNA by intercalation. Plot of relative specific viscosity $(\eta /$ $\left.\eta_{0}\right)^{1 / 3}$ versus [complex]/[DNA] in Fig. 3 shows increase in viscosity of the DNA with the addition of complexes.

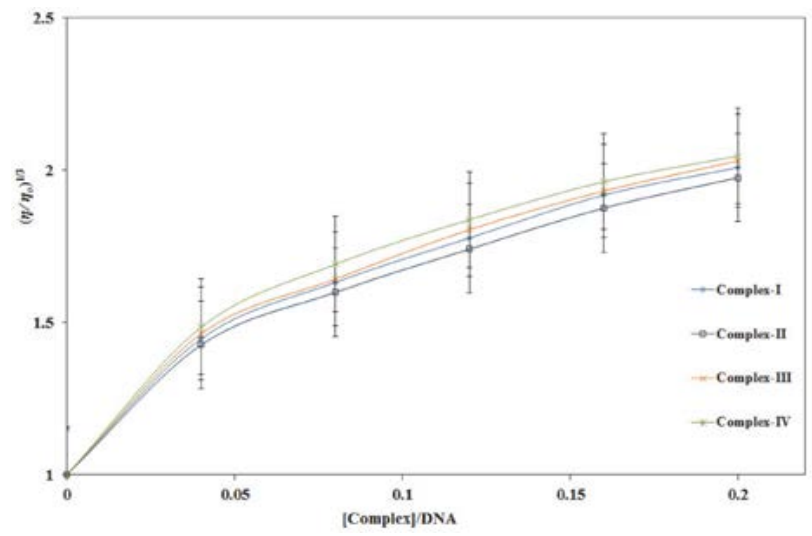

Figure 3. Effect on relative viscosity of HS DNA under the influence of increasing amount of complexes at $37 \pm 0.1{ }^{\circ} \mathrm{C}$ in phosphate buffer ( $\mathrm{pH} 7.2)$ with standard deviation.

\section{5. Orientation of Docked Structure}

Docking study was implemented to determine the orientation and to calculate binding energy of the gold(III) complexes with DNA using HEX 8.0 software. Molecular docking study of the complexes with the B-DNA (PDB ID: 1BNA) duplex of sequence (5'-d(CGCGAATTCGCG)-3') was performed to investigate binding site along with the preferred orientation of complex inside the DNA helix. The study show that the complexes under investigation interact with DNA via an intercalation mode involving outside edge stacking interaction with oxygen atom of the phosphate back bone. From the ensuing docked structures, it is clear that the complexes fit well into the intercalative mode of the targeted DNA and A-T rich region stabilized by van der Waal's interaction and hydrophobic contacts. ${ }^{44}$ The theoretically found binding energies of
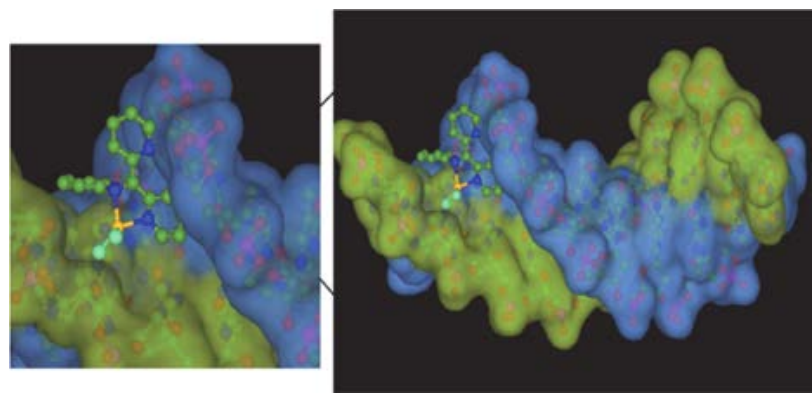

Figure 4. Docked structure of complex I with the HS-DNA duplex of sequence (5'-d(CGCGAATTCGCG)-3')

docked complexes I-IV are -264.01, -229.63, -261.34 and $-261.19 \mathrm{~kJ} \mathrm{~mol}^{-1}$, respectively. The more negative values of the binding energy, more effective binding between DNA and target molecules. ${ }^{45}$ The docking study is shown preferential intercalation binding when complexes interact with DNA. Results obtained by molecular docking suggest similar binding as determined by viscosity measurements and absorption titrations. 


\section{6. Brine Shrimp Lethality Bioassay}

For the discovery and isolation of bioactive compounds with significant cytotoxic potential, the simple and inexpensive methodology employed was Brine shrimp (Artemia cysts) lethality bioassay. ${ }^{34}$ By this activity, we can discover commercially important bioactive compounds. Data were analyzed by the log concentration of sample $v s$ $\%$ mortality of nauplii that gives $\mathrm{LC}_{50}$ values. $\mathrm{LC}_{50}$ values of synthesized ligands and gold(III) complexes in the range of $12.0-26.2 \mu \mathrm{g} / \mathrm{mL}$ and $7.1-12.5 \mu \mathrm{g} / \mathrm{mL}$, respectively. The obtained results were compared with the standard drug cisplatin $\left(\mathrm{LC}_{50}=3.13 \mu \mathrm{g} / \mathrm{mL}\right) .{ }^{46}$ Cytotoxicity of synthesized ligand and complexes are shown in Fig. 5, which suggest that tested compounds exhibit strong ability to interact with the biological model system and the effectiveness of the compound is ordered as follows: cisplatin $>\mathbf{I}>$ IV $>$ II $>$ III $>\mathrm{L}^{1}>\mathrm{L}^{4}>\mathrm{L}^{3}>\mathrm{L}^{2}$. Most of the drugs exert their pharmacological effects by interaction with the biological system through receptors, subcellular components and enzyme. The brine shrimp assay had served the purpose of exploration of numerous pharmacological properties of natural products as well as synthesized compound to serve as a potential candidate for the preparation of effective medicines against various diseases. ${ }^{47}$

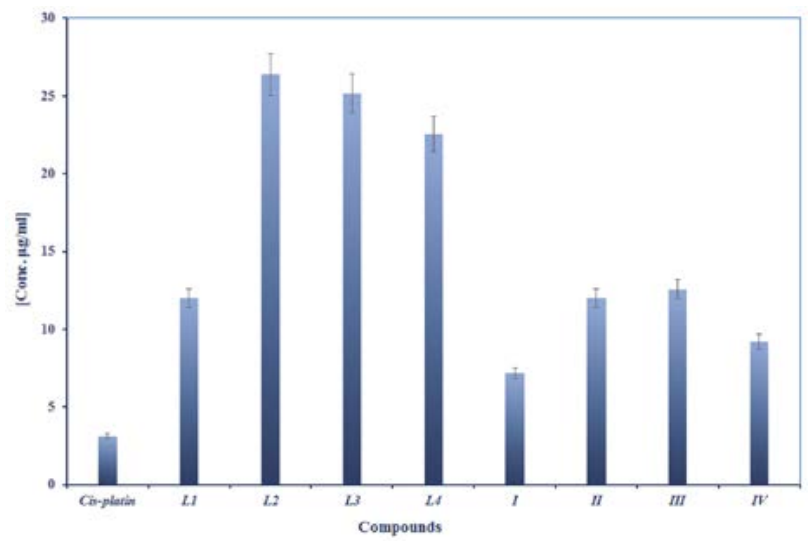

Figure 5. Cytotoxicity of synthesized ligand and complexes by brine shrimp assay.

\section{7. In vivo Cytotoxicity}

Cytotoxic study of synthesized compounds at a cellular level has been carried out through eukaryotic Schizosaccharomyces pombe (S. pombe) cell. ${ }^{44}$ A comparative cytotoxicity of free ligand and their complexes was carried out by trypan blue assay. After 17 hours of the treatment, many of the $S$. pombe cells were killed due to toxic nature of the compound. The observed cytotoxicity data of ligands and complexes are in the range of 76-95\% and 60$88 \%$. From the data recorded, complex I is the most potent amongst all the compounds. From Fig. 6, it is concluded that the synthesized complexes are the good cytotoxic agent than that of respective ligands. The order of potency

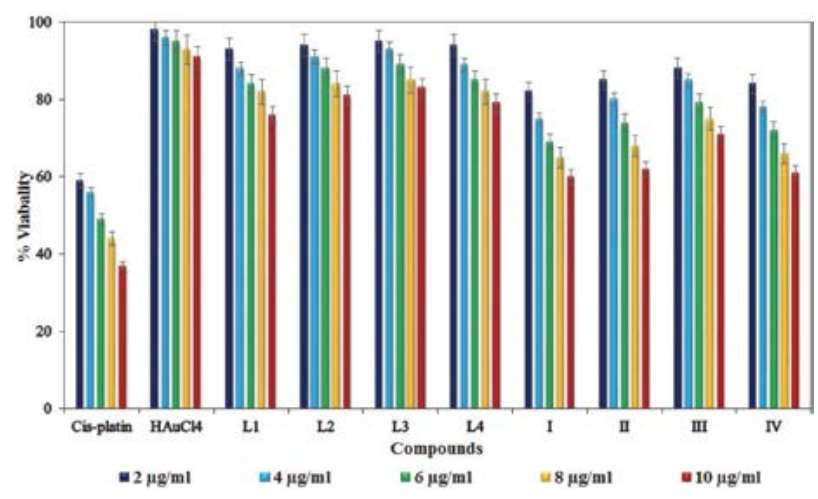

Figure 6. $S$. pombe cell viability represents as the percentage with standard deviation for three independent experiments of synthesized compounds.

of compounds is cisplatin $>$ I $>$ IV $>$ II $>$ III $>\mathrm{L}^{1}>\mathrm{L}^{4}>\mathrm{L}^{3}$ $>\mathrm{L}^{2}>\mathrm{HAuCl}_{4}$. A general reflection of the result is that toxicity varies with the $\mathrm{N}$-donor moiety and as the concentration of compounds increased the cytotoxicity was also increased.

\section{8. Antibacterial Activity}

Bioactivation potentials were evaluated using minimum inhibition concentration (MIC). MIC value is a minimum concentration of compounds that induced a complete growth inhibition. All the synthesized gold(III) complexes (I-IV) have been screened for their antibacterial activity against two Gram $^{(+\mathrm{ve})}$ (Bacillus subtilis (B. subtilis-7193) and Staphylococcus aureus (S. aureus-3160)) and three $\mathrm{Gram}^{(-\mathrm{ve})}$ (Pseudomonas aeruginosa (P. aeruginosa-1688), Escherichia coli (E. coli-433) and Serratia marcescens (S. marcescens-7103)) bacteria. A comparative study of in vitro antibacterial activity of the ligands and their complexes indicates that the metal complexes increase activity against five different bacteria. Reason for this enhancing of antibacterial activity of complexes may be considered in the light of an Overtone's concept ${ }^{44}$ and chelation theory. ${ }^{48}$ As summarized in Figure 7, MIC values of li-

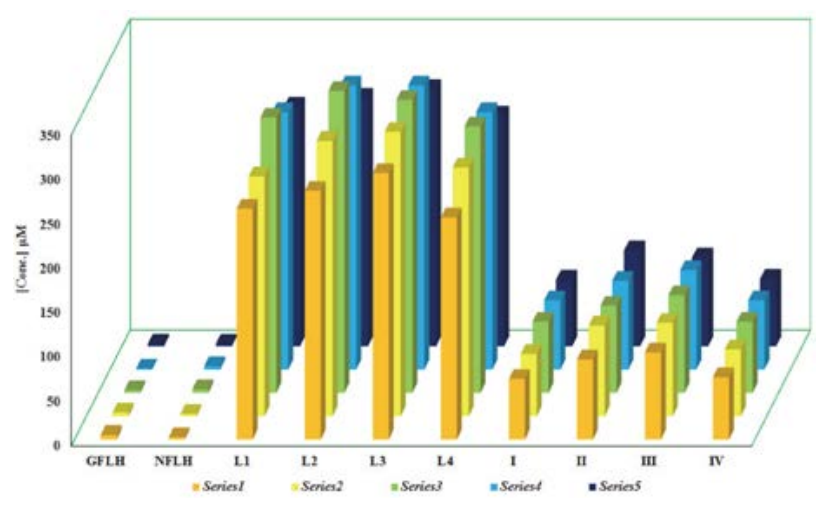

Figure 7. Minimum inhibition concentration (MIC) values of synthesized compounds given in $\mu \mathrm{M}$. 
gands and complexes are in the range of $250-340 \mu \mathrm{M}$ and 68-112 $\mu \mathrm{M}$, respectively. The results show that the complexes are more effective compared to the ligands but less effective compared to the standard drugs gatifloxacin (GFLH) and norfloxacin (NFLH). The complex I and IV are comparatively potent than complex II and III against all bacteria. Antimicrobial activity of cisplatin drug has been reported earlier against $S$. aureus, $P$. aeruginosa and E. coli, and comparable results suggest that synthesized gold(III) complexes are more effective on bacteria. ${ }^{49}$

\section{9. Effect of the Compound on the Integrity of S. pombe Cell's DNA}

DNA extraction has been carried out from S. pombe cells for the study of DNA cleavage by agarose gel electrophoresis. ${ }^{36}$ The effects of the compound on the integrity of DNA are shown in Figure 8.

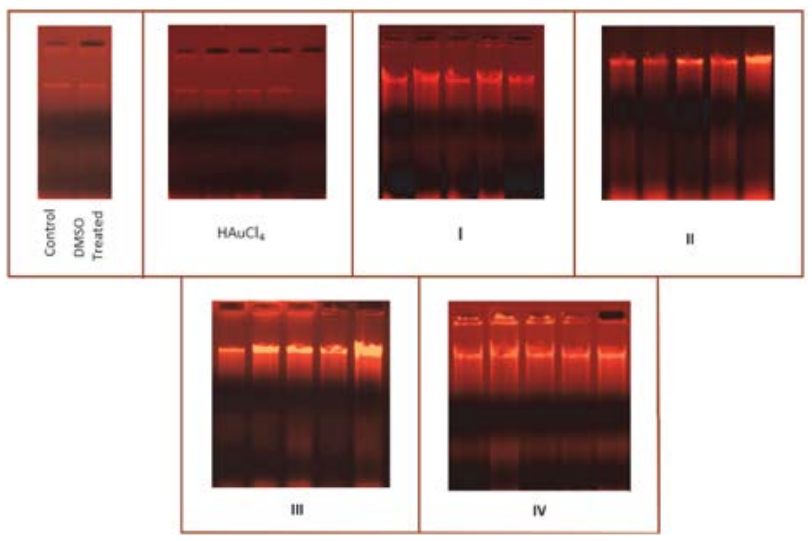

Figure 8. Photogenic view of cleavage of $S$. pombe DNA $\left(1 \mu \mathrm{gL}^{-1}\right)$ with series of compounds using $1 \%$ agarose gel containing $0.5\left(\mu \mathrm{gL}^{-1}\right)$ EtBr. All reactions were incubated in TE buffer $(\mathrm{pH} 8)$ at a final volume of $10 \mu \mathrm{gL}^{-1}$ for $24 \mathrm{~h}$ at $37^{\circ} \mathrm{C}$.

The smearing of DNA in agarose gel suggests that the damage occurs due to the toxic nature of the compound, whereas control cell DNA appeared in the intact band. The complexes exhibit good genotoxicity compare to metal salt and ligands. So, the complexes are toxic at the cellular level and break the DNA from the nucleus to express their toxic effect. The general observation from the Fig. 8 is that the smearing of DNA is increases with the increase in the amount of complexes, which suggests the cytotoxic nature of the complexes.

\section{Conclusion}

In this study, pyridyl moiety based hydrazone $\mathrm{N}-\mathrm{co}-$ ordinating ligand and gold(III) based complexes have been synthesized and characterized by ${ }^{1} \mathrm{H} N M R,{ }^{13} \mathrm{C}$ NMR and IR spectroscopy and LC-MS. The observed values from conductivity measurement and magnetic moment suggest the square planar geometry of gold(III) complexes having one chloride as the counter ion. Electronic absorption titration and viscosity studies suggest intercalation mode of binding between the compound and HS-DNA duplex. Further binding mode verifying by the data generated from docking study promote that intercalating orientation with HS-DNA duplex of sequence (5'-d(CGCGAATTCGCG)-3') ${ }_{2}$. All complexes show strong in vitro and in vivo cytotoxicity and antibacterial activity. Result of DNA cleavage by gel electrophoresis shows DNA smearing due to the toxicity of compounds. The all biological experiments illustrate that the gold(III) complexes as potential biologically active agent. So, this study hypothesize that further detailed investigation of these compounds can explore the potential useful pharmacological effects.

\section{Conflict of Interest}

The authors report no conflicts of interest. The authors alone are responsible for the content and writing of the paper.

\section{Acknowledgments}

The authors thankful to the Head, Department of Chemistry, Sardar Patel University, Vallabh Vidyanagar, Gujarat, India, for providing the laboratory facilities, SAIF Panjab university for C, H, N and ESI-MS analysis, DSTPURSE Sardar Patel University, Vallabh Vidyanagar for LC-MS analysis. U.G.C. New Delhi for providing financial assistance of UGC-BSR grant No. C/2013/BSR/Chemistry/1573.

\section{References}

1. K. C. Nicolaou, D. Rhoades, Y. Wang, R. Bai, E. Hamel, M. Aujay, J. Sandoval, J. Gavrilyuk, J. Am. Chem. Soc. 2017, 139, 7318-7334. DOI:10.1021/jacs.7b02655

2. H.-J. Zhong, L. Lu, K.-H. Leung, C. C. L. Wong, C. Peng, S.C. Yan, D.-L. Ma, Z. Cai, H.-M. David Wang, C.-H. Leung, Chem. Sci. 2015, 6, 5400-5408.

DOI:10.1039/c5sc02321a

3. C. Yang, W. Wang, J.-X. Liang, G. Li, K. Vellaisamy, C.-Y. Wong, D.-L. Ma C.-H. Leung, J. Med. Chem. 2017, 60, $2597-$ 2603. DOI:10.1021/acs.jmedchem.7b00133

4. T. Yang, C. Tu, J. Zhang, L. Lin, X. Zhang, Q. Liu, J. Ding, Q. $\mathrm{Xu}, \mathrm{Z}$. Guo, Dalton Trans. 2003, 3419-3424. DOI:10.1039/B305109A

5. N. Pantelić, B. B. Zmejkovski, J. Trifunović-Macedoljan, A. Savić, D. Stanković, A. Damjanović, Z. Juranić, G. N. Kaluđerović, T. J. Sabo, J. Inorg. Biochem. 2013, 128, 146-153.

DOI:10.1016/j.jinorgbio.2013.08.002 
6. M. N. Patel, B. S. Bhatt, P. A. Dosi, Spectrochim. Acta, Part A 2013, 110, 20-27. DOI:10.1016/j.saa.2013.03.037

7. S. Tabassum, S. Yadav, Inorg. Chim. Acta 2014, 423, 204-214. DOI: $10.1016 /$ j.ica.2014.07.056

8. R. Vafazadeh, A. C. Willis, M. M. Heidari, N. Hasanzade, Acta Chim. Slov. 2014, 62, 122-129. DOI: 10.17344/acsi.2014.797

9. V. Amani, A. Abedi, S. Ghabeshi, H. R. Khavasi, S. M. Hosseini, N. Safari, Polyhedron 2014, 79, 104-115.

DOI: $10.1016 /$ j.poly.2014.04.064

10. C. D. Sanghvi, P. M. Olsen, C. Elix, S. Peng, D. Wang, Z. Chen, D. M. Shin, K. I. Hardcastle, C. E. MacBeth, J. F. Eichler, J. Inorg. Biochem. 2013, 128, 68-76.

DOI:10.1016/j.jinorgbio.2013.07.014

11. A. E. Finkelstein, D. T. Walz, V. Batista, M. Mizraji, F. Roisman, A. Misher, Ann. Rheum. Dis. 1976, 35, 251-257.

12. P. N. Fonteh, F. K. Keter, D. Meyer, J. Inorg. Biochem. 2011, 105, 1173-1180. DOI:10.1016/j.jinorgbio.2011.05.011

13. K. Fourmy, M. Gouygou, O. Dechy-Cabaret, F. Benoit-Vical, C. R. Chim. 2017, 20, 333-338. DOI:10.1016/j.crci.2016.06.008

14. T. V. Serebryanskaya, A. S. Lyakhov, L. S. Ivashkevich, J. Schur, C. Frias, A. Prokop, I. Ott, Dalton Trans. 2015, 44, 1161-1169. DOI:10.1039/C4DT03105A

15. U. Ndagi, N. Mhlongo, M. E. Soliman, Drug. Des. Devel. Ther. 2017, 11, 599-616. DOI:10.2147/DDDT.S119488

16. V. Milacic, Q. P. Dou, Coord. Chem. Rev. 2009, 253, 16491660. DOI:10.1016/j.ccr.2009.01.032

17. C. Marzano, L. Ronconi, F. Chiara, M. C. Giron, I. Faustinelli, P. Cristofori, A. Trevisan, D. Fregona, Int. J. Cancer 2011, 129, 487-496. DOI:10.1002/ijc.25684

18. C. Nardon, G. Boscutti, D. Fregona, Anticancer Res. 2014, 34, 487-492.

19. C. Martín-Santos, E. Michelucci, T. Marzo, L. Messori, P. Szumlas, P. J. Bednarski, R. Mas-Ballesté, C. Navarro-Ranninger, S. Cabrera, J. Alemán, J. Inorg. Biochem. 2015, 153, 339-345. DOI:10.1016/j.jinorgbio.2015.09.012

20. B. D. Glisic, M. I. Djuran, Dalton Trans. 2014, 43, 5950-5969. DOI:10.1039/C4DT00022F

21. S. Iwashita, Y. Saito, H. Ohtsu, K. Tsuge, Dalton Trans. 2014, 43, 15719-15722. DOI:10.1039/C4DT02279C

22. S. J. Sabounchei, P. Shahriary, S. Salehzadeh, Y. Gholiee, D. Nematollahi, A. Chehregani, A. Amani, New J. Chem. 2014, 38, 1199-1210. DOI:10.1039/C3NJ01042B

23. K. N. Kouroulis, S. K. Hadjikakou, N. Kourkoumelis, M. Kubicki, L. Male, M. Hursthouse, S. Skoulika, A. K. Metsios, V. Y. Tyurin, A. V. Dolganov, E. R. Milaeva, N. Hadjiliadis, Dalton Trans. 2009, 10446-10456. DOI:10.1039/B909587J

24. S. Wang, W. Shao, H. Li, C. Liu, K. Wang, J. Zhang, Eur. J. Med. Chem. 2011, 46, 1914-1918.

DOI:10.1016/j.ejmech.2011.02.031

25. M. Bakir, O. Green, M. Wilmot-Singh, J. Mole. Struct. 2010, 967, 174-182. DOI:10.1016/j.molstruc.2010.01.005

26. G. Tamasi, L. Chiasserini, L. Savini, A. Sega, R. Cini, J. Inorg. Biochem. 2005, 99, 1347-1359.

DOI: $10.1016 /$ j.jinorgbio.2005.03.009

27. A. A. R. Despaigne, J. G. d. Silva, A. C. M. d. Carmo, F. Sives,
O. E. Piro, E. E. Castellano, H. Beraldo, Polyhedron 2009, 28, 3797-3803. DOI:10.1016/j.poly.2009.07.059

28. V. T. Angelova, V. Valcheva, N. G. Vassilev, R. Buyukliev, G. Momekov, I. Dimitrov, L. Saso, M. Djukic, B. Shivachev, Bioorg. Med. Chem. Lett. 2017, 27, 223-227.

DOI:10.1016/j.bmcl.2016.11.071

29. K. El-mahdy, A. El-Kazak, M. Abdel-Megid, M. Seada, O. Farouk, Acta Chim. Slov. 2016, 63, 18-25.

DOI:10.17344/acsi.2015.1555

30. P. A. Dosi, M. N. Patel, B. S. Bhatt, Acta Chim. Slov. 2012, 59, 622-631.

31. G. Cohen, H. Eisenberg, Biopolymers 1969, 8, 45-55. DOI:10.1002/bip.1969.360080105

32. S. Mondal, B. Pakhira, A. J. Blake, M. G. B. Drew, S. K. Chattopadhyay, Polyhedron 2016, 117, 327-337.

DOI:10.1016/j.poly.2016.05.052

33. M.-L. Liu, M. Jiang, K. Zheng, Y.-T. Li, Z.-Y. Wu, C.-W. Yan, J. Coord. Chem. 2014, 67, 630-648.

DOI:10.1080/00958972.2014.884218

34. B. N. Meyer, N. R. Ferrigni, J. E. Putnam, L. B. Jacobsen, D. E. Nichols, J. L. McLaughlin, Planta Med. 1982, 45, 31-34. DOI:10.1055/s-2007-971236

35. J. V. Mehta, S. B. Gajera, M. N. Patel, J. Biomole. Struct. Dyn. 2016, 1-9. DOI:10.1080/07391102.2016.1189360

36. P. B. Patel, V. Thakkar, Asian J. Cell Biol. 2013, 8, 22-32. DOI:10.3923/ajcb.2013.22.32

37. R. Křikavová, J. Hošek, P. Suchý, J. Vančo, Z. Trávníček, J. Inorg. Biochem. 2014, 134, 92-99.

DOI:10.1016/j.jinorgbio.2014.02.002

38. R. W.-Y. Sun, C.-M. Che, Coord. Chem. Rev. 2009, 253, 1682 1691. DOI:10.1016/j.ccr.2009.02.017

39. M. Frik, J. Fernández-Gallardo, O. Gonzalo, V. Mangas-Sanjuan, M. González-Alvarez, A. Serrano del Valle, C. Hu, I. González-Alvarez, M. Bermejo, I. Marzo, M. Contel, J. Med. Chem. 2015, 58, 5825-5841.

DOI:10.1021/acs.jmedchem.5b00427

40. A. N. Wein, A. T. Stockhausen, K. I. Hardcastle, M. R. Saadein, S. Peng, D. Wang, D. M. Shin, Z. Chen, J. F. Eichler, J. Inorg. Biochem. 2011, 105, 663-668.

DOI:10.1016/j.jinorgbio.2011.01.006

41. S. Mistri, H. Puschmann, S. C. Manna, Polyhedron 2016, 115, 155-163. DOI:10.1016/j.poly.2016.05.003

42. M. Gaber, H. A. El-Ghamry, S. K. Fathalla, Spectrochim. Acta, Part A 2015, 139, 396-404. DOI:10.1016/j.saa.2014.12.057

43. M. N. Patel, M. R. Chhasatia, D. S. Gandhi, Bioorg. Med. Chem. Lett. 2009, 19, 2870-2873.

DOI:10.1016/j.bmcl.2009.03.078

44. J. V. Mehta, S. B. Gajera, P. Thakor, V. R. Thakkar, M. N. Patel, RSC Adv. 2015, 5, 85350-85362. DOI:10.1039/C5RA17185G

45. N. Deepika, C. S. Devi, Y. P. Kumar, K. L. Reddy, P. V. Reddy, D. A. Kumar, S. S. Surya, S. Satyanarayana, J. Photochem. Photobiol., B 2016, 160, 142-153.

DOI: $10.1016 /$ j.jphotobiol.2016.03.061

46. M. V. Lunagariya, K. P. Thakor, D. N. Kanthecha, M. N. Patel, J. Organomet. Chem. 2018, 854, 49-63.

DOI:10.1016/j.jorganchem.2017.11.012 
47. M. N. Ahmed, K. A. Yasin, K. Ayub, T. Mahmood, M. N. Tahir, B. A. Khan, M. Hafeez, M. Ahmed, I. ul-Haq, J. Mol. Struct. 2016, 1106, 430-439.

DOI:10.1016/j.molstruc.2015.11.010
48. B. Tweedy, Phytopathology 1964, 55, 910-914.

49. N. Chowdhury, T. L. Wood, M. Martínez-Vázquez, R. García-Contreras, T. K. Wood, Biotechnol. Bioeng. 2016, 113, 1984-1992. DOI:10.1002/bit.25963

\section{Povzetek}

Sintetizirane ligande in komplekse, $\left[\mathrm{Au}\left(\mathrm{L}^{\mathrm{n}}\right) \mathrm{Cl}_{2}\right] \mathrm{Cl}$, smo okarakterizirali z različnimi tehnikami, kot so elementna analiza, LC-MS, FT-IR, UV-Vis, ${ }^{1} \mathrm{H}$ in ${ }^{13} \mathrm{C}$ NMR spktroskopija, merjenje prevodnosti in magnetnega momenta. Eksperimentalni rezultati kažejo, da imajo kompleksi višjo antibakterijsko aktivnost proti Gram(+) in Gram(-) mikroorganizmom kakor prosti ligandi. In vitro citotoksičnost in citotoksičnost na celičnem nivoju kažeta, da imajo Au(III) kompleksi boljše aktivnosti kakor ligandi. Študija interakcij z DNA je bila izvedena z absorpcijsko titracijo. Na podlagi eksperimentalnih podatkov $\left(K_{\mathrm{b}}=1.08-3.44 \cdot 10^{5} \mathrm{M}^{-1}\right)$ sklepamo, da se vsi kompleksi interkalirajo na HS-DNA. Za dodatno potrditev narave interakcij smo izvedli meritve viskoznosti in tudi molekulsko modeliranje. Spremljali smo tudi cepitev DNA pri Schizosaccharomyces pombe na agarose gelu, pri čemer posnetki kažejo cepitev DNA. 